\title{
Identificação das feições rasas de gás na região da Lagoa da Conceição e da Baía Norte na llha de Santa Catarina
}

Vanessa Guesser ${ }^{* 1}$ - nessaguesser@hotmail.com

Larissa F. W. Demarco ${ }^{1}$, Antonio H. F. Klein ${ }^{1}$, Arthur A. Neto ${ }^{2}$, César Felix ${ }^{3}$, Jorge Souza ${ }^{3}$, Jarbas Bonetti ${ }^{1}$.

${ }^{1}$ Universidade Federal de Santa Catarina ${ }^{2}$ Universidade Federal Fluminense ${ }^{3}$ Grupo SHAW.

Copyright 2012, SBGf - Sociedade Brasileira de Geofísica

Este texto foi preparado para a apresentação no V Simpósio Brasileiro de Geofísica, Salvador, 27 a 29 de novembro de 2012. Seu conteúdo foi revisado pelo Comitê Técnico do V SimBGf, mas não necessariamente representa a opinião da SBGf ou de seus associados. É proibida a reprodução total ou parcial deste material para propósitos comerciais sem prévia autorização da SBGf.

\section{Abstract}

This paper presents the identification and depth of gas features detected in the Conceição Lagoon and in the North Bay, located on the Island of Santa Catarina, Brazil. The lines were obtained by seismic acoustic profiler of high resolution, using the equipment CHIRP (frequency between 1 and $16 \mathrm{KHz}$ ), then the data were spatially processed and interpreted with the use of free software. The high resolution seismic data showed the presence of shallow gas classified as Acoustic blanket (acoustic blanking), Turbidity pinnacles, Intra-sedimentary plumes, Black shadows and gas escape as Acoustic plumes.

\section{Introdução}

Estruturas rasas de gás são formadas conforme características do ambiente de sedimentação, juntamente com os processos evolutivos (períodos geológicos antigos), devido a uma intensa oxidação de matéria orgânica acumulada sob efeito de altas pressões e temperaturas. Eventos transgressivos e regressivos ao longo dos períodos geológicos podem alterar de diversas formas esse ambiente de sedimentação, de maneira a modificar a distribuição e quantidade da matéria orgânica disponível no local, a qual proporcionará a formação dos diversos tipos de gases. A acumulação destes gases pode ser na superfície ou subsuperfície da coluna sedimentar, ou podem estar dissolvidos na coluna de água. Estruturas rasas de gás são acumuladas em diversas feições geomorfológicas, na forma de coberturas acústicas, cortinas acústicas, colunas acústicas, turbidez acústica, entre outros (Frazão et. al., 2007). Os escapes de gás também apresentam uma feição característica, podendo ser na forma de plumas acústicas, pockmarks, entre outros (Frazão et. al., 2007). A distribuição espacial destes diferentes tipos de acumulações depende do tamanho do grão, porosidade e do tipo de sedimento ou rocha na qual os gases estão presos. Provavelmente a porosidade nas fáceis sedimentares onde o gás se acumula e as fáceis selantes são os principais fatores que determinam o tipo de acumulação de gás (Frazão et. al., 2007). A utilização da geofísica para a busca de jazidas, gás e petróleo tem se intensificado nas últimas décadas. Os métodos geofísicos constituem métodos indiretos de investigação que tem especial relevância quando da investigação de áreas submersas. Alguns dos motivos seriam que estes métodos constituem um conjunto de ensaios que possibilitam visão mais ampla e contínua da subsuperfície investigada. Outro bom motivo é o fato de que esses métodos são ensaios não destrutivos ou não invasivos, pois as informações são obtidas a partir da superfície, sem a necessidade da penetração física no meio investigado (Souza, 2006). A resolução dos registros sísmicos depende da feição na qual o gás está acumulado, e o acúmulo destas estruturas rasas de gás é devido à quantidade de matéria orgânica disponível no local. Acosta (1984) apud Frazão et al. (2007) sugeriu que $7 \%$ da matéria orgânica são o mínimo para gerar gás suficiente para mascarar o registro sísmico. O presente resumo tem por objetivo a descrição dos bolsões de gases e o cálculo da profundidade onde estes se encontram, localizados na Lagoa da Conceição e na Baía Norte na Ilha de Santa Catarina, Santa Catarina, Brasil.

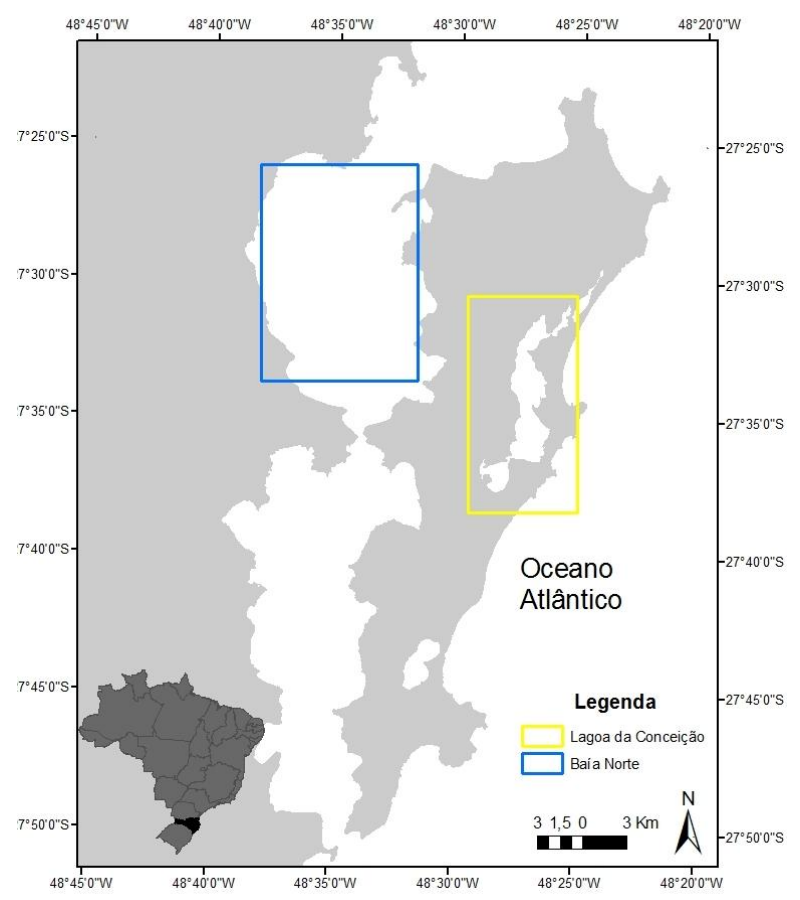

Figura 1 - Descrição da área de estudo. Fonte Mapoteca Epagri

\section{Metodologia}

As linhas sísmicas foram aquisitadas na região da Lagoa da Conceição e na Baía Norte, localizadas na llha de Santa Catarina, Santa Catarina, Brasil. Na Baía Norte 
foram obtidos $83,26 \mathrm{Km}$ de linhas sísmicas de um perfilador acústico do tipo CHIRP, com frequência de trabalho entre 2 e $16 \mathrm{KHz}$. Na Lagoa da Conceição as linhas sísmicas foram aquisitadas utilizando-se um CHIRP com frequência de trabalho entre 1 e $6 \mathrm{KHz}$. Os dados foram processados e interpretados através dos softwares livres SeisPrho e SeiSee, sendo espacializados com o auxilio do software ArcGis. Com isso, foi possível a identificação das feições nas quais os gases estão acumulados na região de estudo.

\section{Resultados}

$\mathrm{Na}$ região da Lagoa da Conceição (Fig.2) foram constatados a presenças dos gases rasos na forma de acumulações e escapes com a presença de feições rasas de gás em 25 perfis. As acumulações de gases estavam na forma de Coberturas Acústicas, feição caracterizada como um forte refletor de topo mostrando uma completa ausência de dados sísmicos abaixo (Lee et al., 2005), ou seja, existe um mascaramento completo do registro sísmico subjacente, impossibilitando determinar a estratigrafia ou a conexão com uma fonte de gás.

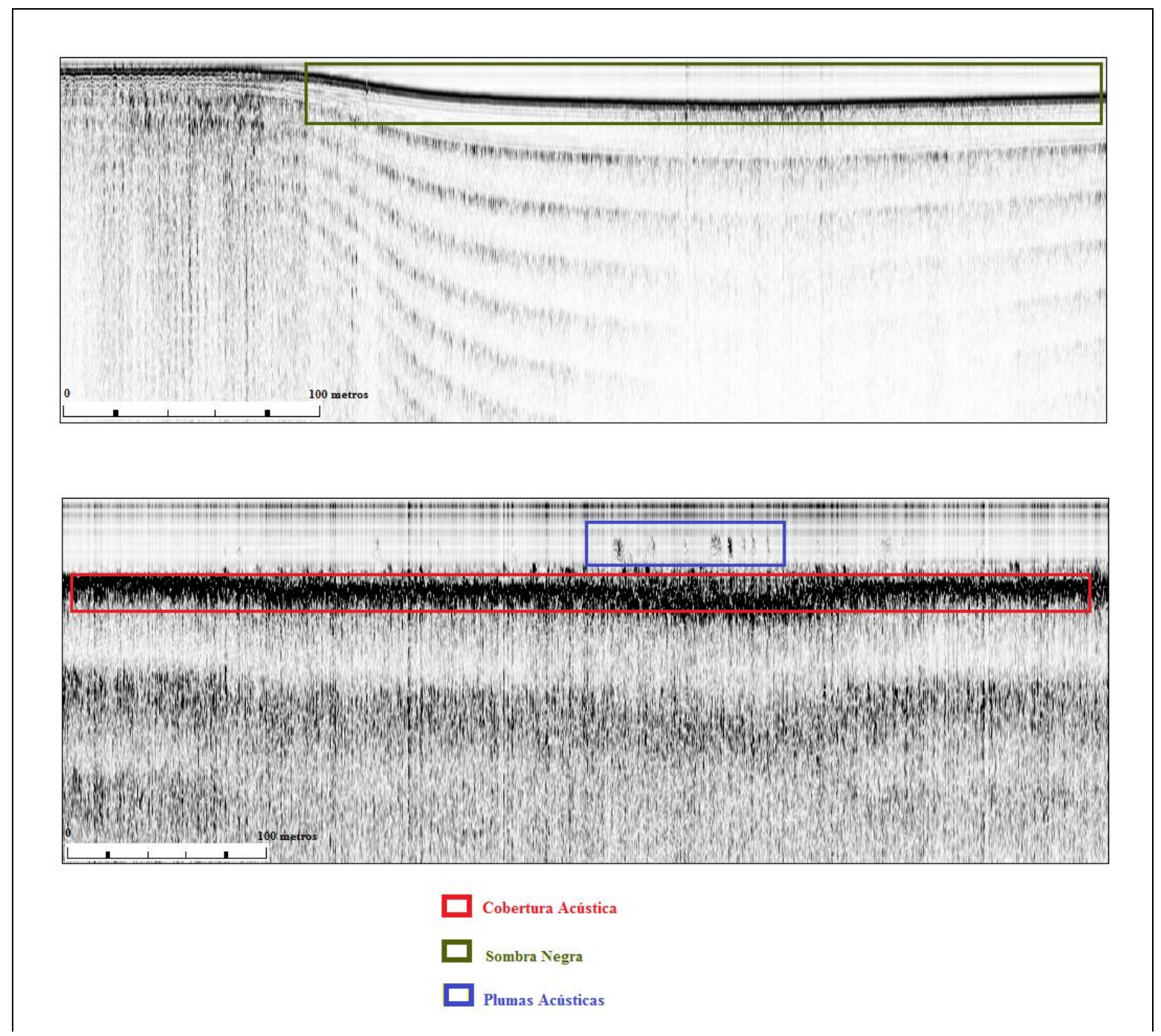

Figura 2 - Feições de gases encontradas na Lagoa da Conceição na forma de cobertura acústica, sombra negra e plumas acústicas.

Além de apresentar Sombras Negras, as quais são feições de gases que se diferenciam da cortina acústica por atingir o fundo marinho (Baltzer et al., 2005). Foi encontrado escape de gás em 2 perfis na forma de Plumas Acústicas que consistem em uma série de reflexões parabólicas de alta amplitude com uma freqüência de ocorrência ao longo da linha sísmica de tipicamente a cada 100-200 metros (Taylor (1992) apud Frazão et. al. (2007)). Ao identificar as feições, calculouse a profundidade das mesmas, estando 15 perfis na superfície, 5 perfis localizados em uma profundidade entre 0,24 e 0,66 metros, 5 perfis contidos em uma profundidade entre 1,00 e 1,47 metros. 
Na Baía Norte (Fig.3) dos 142 perfis, 45 apresentaram presença de gás. Sendo que na porção Norte, próximo ao estreitamento da Baía os gases apresentam profundidades entre 0,8 e $3 m$ e estão na forma de Coberturas Acústicas, onde alguns pontos possuem associações de Pináculos de Turbidez, que de acordo com Garcia Gil et al. (2002), são uma variação da frente da Cobertura Acústica que aparece como em forma de tenda, obscurecendo completamente os refletores subjacentes que sobem até $1 \mathrm{~m}$ acima da média dos gases, às vezes atingindo o fundo do mar. A parte central da Baía apresenta gases com profundidade de $0,7 \mathrm{~m}$ até a superfície, com predomínio de Coberturas Acústicas com presença de Pináculos de Turbidez e Plumas intrasedimentares, as quais são feições que consistem de anomalias parabólicas atravessando refletores reais (Garcia Gil et al., 2002), que na Baía se tornam cada vez mais próximo da superfície.

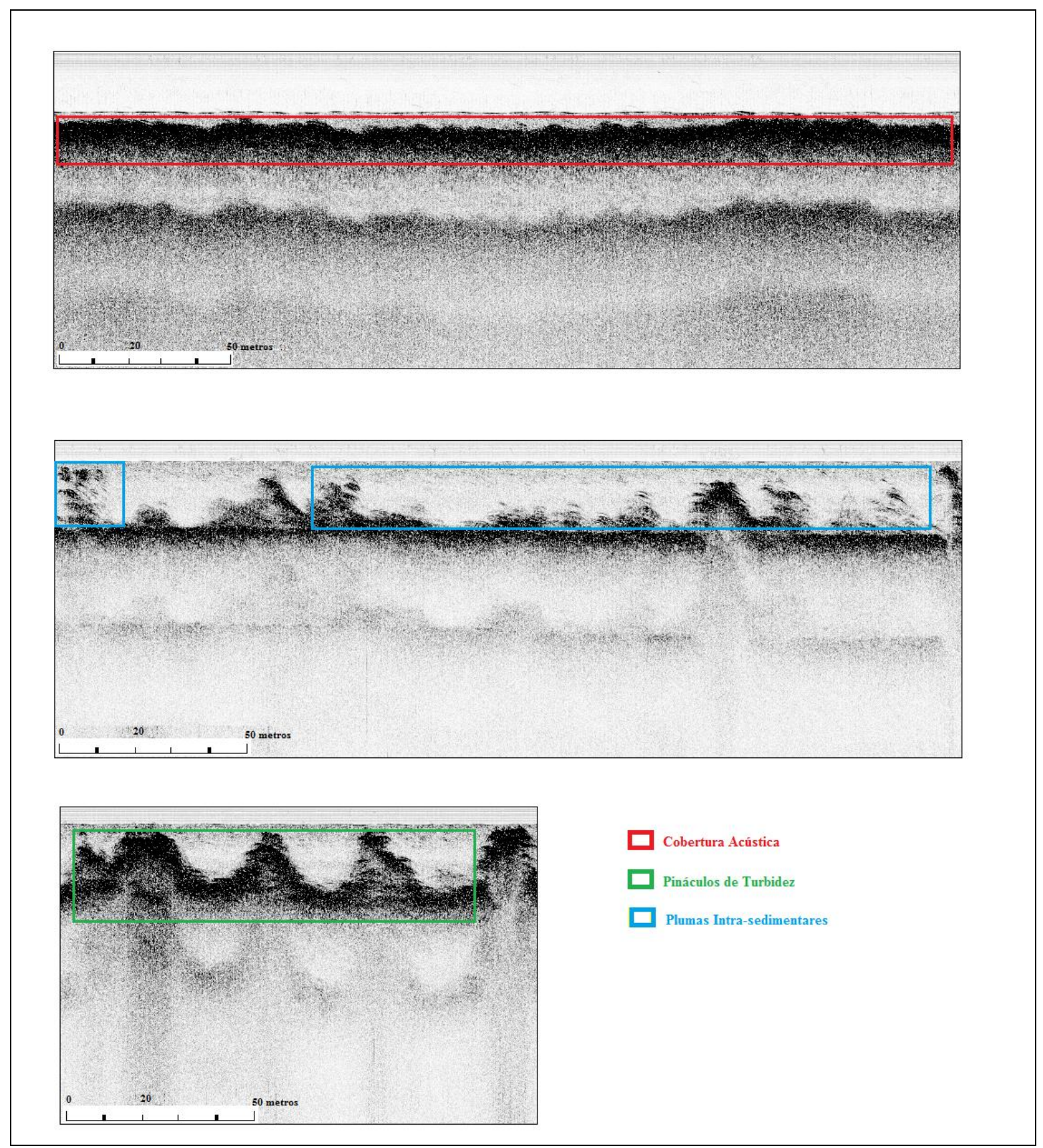

Figura 3 - Feições de gases encontradas na Baía Norte na forma de cobertura acústica, pináculos de turbidez e plumas intra-sedimentares. 


\section{Discussão e Conclusões}

A importância do estudo das estruras de gás raso (shallow gas) é devido à busca constante de se obter energia, principalmente através de hidratos de gás, óleo e exploração de gás. Segundo Best et. al. (2006) apud Frazão et al. (2007) essas estruturas também são importantes para as mudanças climáticas. Os constituintes da matéria orgânica, como os teores de carbono orgânico (CO), nitrogênio total (NT), enxofre total (ST) podem ser utilizados como indicadores geoquímicos da origem, importância e estado de degradação destes compostos nos sedimentos costeiros (Barcellos (2005) apud Bonetti, C. et al. (2007)). Com a descrição dos gases rasos finalizada, é possível calcular qual o volume que estes ocupam no ambiente estudado, com isso, estabelecer os possíveis danos causados por estes gases se estes forem liberados para a atmosfera.

A presença de bolsões de gases na porção central da Baía Norte da llha de Santa Catarina parecem coincidir com a concentração de enxofre total (SO4) nos sedimentos de superfície, que é comparativamente maior do que os seus arredores (Souza et. al., 2011). Sendo esta área identificada como as de menores profundidades de localização dos gases, chegando em alguns pontos até a superfície, o que nos remete a uma área mais suscetível ambientalmente.

$\mathrm{Na}$ Lagoa da Conceição os bolsões de gases estão distribuídos ao longo das 25 de 30 linhas sísmicas realizadas, sendo que a maioria dos perfis, que contem gases (15 linhas sísmicas), está em superfície. Deste modo, tornando estas áreas mais capazes à liberação destes gases para o ambiente.

\section{Agradecimentos}

Os autores agradecem pela cessão das linhas sísmicas da lagoa da Conceição pelo projeto CNPq: RECONSTITUIÇÃO DE PALEOAMBIENTES QUATERNÁRIOS DA LAGOA DA CONCEIC̃̃O (SC) BASEADA NA DISTRIBUIÇÃO DE FORAMINÍFEROS E INDICADORES SEDIMENTOLÓGICOS. Processo CNPq $n^{\circ}: 401851 / 2010-9$. E pela cessão das linhas sísmicas da Baía Norte pelo Grupo SHAW.

\section{Referências}

Baltzer, A., Tessier, B., Nouze, H., et al., 2005. Seistec seismic profiles: A tool to differentiate gas signatures. Marine Geophysical Researches 26, 235-245.

Bonetti, C., Bonetti, J. \& Barcelos, R. L., 2007. Caracterização sedimentar e geoquímica de sistemas costeiros com ênfase na avaliação da influência de sítios de cultivo de moluscos. Museu Nacional, cap. 15, pag. $139-149$.

Frazão, E. \& Vital, H., 2007. Estruturas rasas de gás em sedimentos no estuário Potengi (nordeste do Brasil).

RevistaBrasileira de Geofísica, no 25, pag. 17 - 26.
Garcia-Gil, S., Vilas, F. \& Garcia-Garcia, A., 2002. Shallow gas features in incised-valley fills (Ría de Vigo, NW Spain): a case study. Continental Shelf Research, no 22, pag. $2303-2315$.

Lee, G.H. et al., 2005. Shallow gas in the central part of Korea strait shelf mud off the southeastern coast of Korea. Cont. Shelf Res. 25, 2036-2052

Souza, J. et al., 2011. Gas features detected with ultra shallow water high resolution seismic in the North Bay, Santa Catarina State, Southern Brazil. In: XIV Congresso Latino-Americano de Ciências do Mar, 2011, Balneário Camboriu. Anais... Balneário Camboriu: COLACMAR, 2011. CD-ROM.

Souza, L. A. P., 2006. Revisão crítica da aplicabilidade dos métodos geofísicos na investigação de áreas submersas rasas. Instituto Oceanográfico da Universidade de São Paulo, USP, 2006, 311 pag. Tese de doutorado. 